\title{
THE DYNASTIC HISTORY OR NARANJO: THE EARLY PERIOD
}

\author{
Michael P. Cross \\ Department of Mathematics \\ University of Ottawa \\ Ottawa, Canada \\ November, 1981 \\ Revised May, 1982
}

\section{Introduction}

A number of articles have been published which give glimpses into the dynastic history of Naranjo (Proskouriakoff, 1960; Berlin, 1968 and 1973; Beetz, 1980). However, none of these were devoted solely to elucidating the historical data in the Naranjo inscriptions. The Naranjo material is difficult to study because of the poor state of preservation of many Naranjo monuments. Earlier researchers also had difficulty in obtaining satisfactory pictorical records of these inscriptions. Although the former problem cannot be helped, the latter has been remedied by the appearance of Parts 1 and 2 of Volume 2 of the Corpus of Maya Hieroglyphic Inscriptions (Graham and Von Euw, 1975 and Graham, 1978).

In 1979, I completed a study of the chronological data in the Naranjo inscriptions. It was apparent from this work that, as earlier realized by Morley (1937-1938), the monuments at the site fall into three general periods. An early period accounts for monuments sculptured from 9.8.0.0.0 to 9.10.10.0.0, a middle period for those from 9.13.10.0.0 to 9.15.0.0.0, and a late period for those from 9.17.10.0.0 to 9.19 .10 .0 .0 The earliest date which may be attributed to the middle period at Naranjo is at 9.12.10.5.12. It is an important date recorded 
on four different monuments, namely Stelae 3, 18, 24 and 29. There is thus a gap of some 40 years between the last monument erected in that early period and the first reference to renewed activity in the middle period. Another gap or approximately 40 years separates the latest date in the middle period from the earliest date in the late period. There is a possibility that the dates on Stelae 6 and 37 fall into the interval separating the middle and late periods, but a secure placement of these is problematic.

The present paper is concerned with the dynastic happenings in the early period at Naranjo. There are six monuments from the site which contain hieroglyphic texts sufficiently well preserved to shed light on this early history. Four of these [Altar 1, Stelae 25, 27 and 38] are associated with the reign of a single ruler whom I shall label "Chief Double-Comb". The remaining two [Lintel 1 and the Hieroglyphic Stairway] are associated with a Caracol ruler known as Lord Storm-water Moon. A summary of the dates on all six monument. is presented in Table 1. The Long Count positions are listed it chronological order and are cross-referenced by monument and by ruler.

\section{Chief Double-Comb}

The name glyph of Chief Double-Comb is illustrated in Fig. 1a. It occurs eight times on the monuments of the early period [Stela 25, A7; Stela 27, Ap2a; Stela 38, A4 and B8; Altar 1, G2, I4, I11 and $\mathrm{J10}$ ] and twice on the monuments of the middle period (Stela 3, E14; Stela 31, 19]. It can be recognized as the name of a Naranjo ruler because in at least three of its appearances it is the only glyph which intervenes between the Naranjo emblem glyph and a preceding chronological phrase. Two of these associations with the emblem glyph are well preserved and are shown in Fig. 1, b-c. A full-figure portrait of Double-Comb, now faceless, appears on Stela 38.

\section{The birth of Chief Double-Comb}

Birth and accesion to power are the two life events which are most commonly recorded on the monuments of Maya rulers. References to births were first isolated by observing that the earliest dates 
in the presumed reigns of rulers were usually marked with a common event glyph, T740, shown in Fig. 1d (Proskouriakoff, 1960). More recently, the occasional use of an alternate expression for the birth event, T204.217:526. shown in Fig. 1e, has been noted at Palenque (Lounsbury, 1980:112). In the present case, the earliest clause referring to Double-Comb, from Altar 1, is reproduced in Fig. 2, together with a brief framed text and design which interrupts the clause. It can be seen that clause employs neither of the recognized glyphs for birth. Nevertheless, there are reasons for believing that this is the event being recorded. The event glyph in Fig. 2 occurs at F1. It is repeated in the following clause as a prior event glyph and, for purposes of comparison, this second occurrence is shown in Fig. 1f. The glyph combination opens with a T80 prefix, of which the initial element corresponds to the Maya term mol, "collect, gather", and to the phonetic value mo- This is followed by a tun glyph, T528.116, representing a period of 360 days. However, this variant of the tun glyph is not used in chronological counts as a period glyph. Rather, it is used in expressions which record a state of the Long Count (or sometimes, an anniversary count) in which subsidiary counts of uinats (20-day periods) and kins (days) are void. Thus, its usage is restricted to phrases whose dates are separated from the base date of the Long Count or the base of an anniversary count by an integral count of tuns and its purpose is to indicate the status of this tun count. Next in order is a T16, yax, "new, fresh, green" prefix attached to a glyph with a T48 postfix. The main sign corresponds to a detail found in the three panels of the Cross Group at Palenque where it seems to serve as a gathering clasp for cloth drapery worn by the smaller figure in each panel. If the various components of the event glyph are assembled according to the standard order in Maya writing, it is possible to interpret the glyph as signifying "collects (?) ... the count of the tun in a new gathering device (?)". The sense may be that a tun count was newly begun on the date of the clause, a clause whose protagonist is Double-Comb. Thus, the event glyph may record that the enumeration of Double-Comb's personal chronology begins on the date in question, an apt metaphor for birth.

A second argument favouring a birth reference for the clause in Fig. 2 comes from an analysis of dates associated with Double-Comb. The clause being examined has the earliest date and is fixed in the Long Count at 9.4.10.8.17. By contrast, the latest historical date

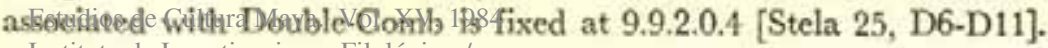
Instituto de Investigaciones Filológicas/

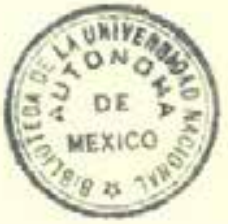


The interval between the earliest and latest dates is 4.11.9.7, that is, a little over 90 years. If the earliest date is not the birth date of Double-Comb, then his life span must be extended accordingly, a process which is severely limited by his already advanced age.

A final angument that the text in Fig. 2 is a birth clause stems from its possible relationship to a clause from the middle period at Naranjo. The monuments erected during this period fall within the reign of a Maya ruler known at Smoking Squirrel. His name glyph is exhibited in Fig. 1g. It can be assumed that Smoking Squirrel regarded Double-Comb with admiration since the former referred to the latter on two of the monuments of the middle period [Stela 3, E14; Stela 31, 19]. Interestingly, a birth clause of Smoking Squirrel, recorded on one of the earliest monuments of his reign, closely imitates the presumed birth clause of Double-Comb. The two clauses are illustrated in a format which facilitates comparison in Fig. 3. The glyph at G1 on Altar 1 precedes the name of Smoking Squirrel on Stela 22 at G16 and on Stela 23 at F14 and G11, although it is absent in the clause from Stela 24 in Fig. 3. In addition, the Naranjo emblem glyph on Stela 24 at C14 follows the name of Double-Comb on Stela 38 at A9, although it is absent in the clause from Altar 1 in Fig. 3. The glyph at E10 on Altar 1 is one of at least 18 occurrences, some with minor variations, confined to the early and late periods at Naranjo. It is not found at other sites. In eight cases it replaces the Naranjo emblem glyph and in another six cases it appears adjacent to the emblem glyph. Evidently, it functions as a Naranjo rulership title. The apparently close relationship between the two clauses argues in favour of the earlier being a birth clause, as is the later, and suggests that the later might even have been intended to imitate the earlier.

\section{The accession of Chief Double-Comb}

Although a variety of accession phrases have been isolated in Maya texts, none of these can be recognized in the inscriptions dedicated to Double-Comb. However, there is an alternate approach which can be used, at times, to retrieve accession dates of Maya rulers. This derives from the frequent practice of commemorating accessions with anniversary counts. For example, in Proskouriakoff's (1960) study of Piedras Negras dates, she noted three anniversaries of initial or birth dates and at least seven anniversaries of inaugural 
dates at that site. Accordingly, when an anniversary is celebrated and does not commemorate a birth, it is very likely that it refers to a ruler's inauguration. In the case of the early period at Naranjo, there are conspicuous anniversaries recorded on Stela 25. These mark the 1 katun, 2 katun and 3 katun anniversaries of the date $6 \mathrm{Kan} 2 \mathrm{Zip}$ having Long Count position 9.5.12.0.4. At this time, Double-Comb would have been a little more than 21 years of age and the importance of the date suggests that it is probably the date of his inauguration as ruler of Naranjo.

Strong support for this position comes from a later inscription of Smoking Squirrel on Stela 3. The terminal clause on this monument can be readily translated as follows:

$\begin{array}{ll}\text { F11-E12 } & \text { [On] (4 Kan) } 7 \text { Pax }[9.6 .12 .0 .4] \\ \text { F12-E13 } & \text { [it was] } 15 \text { [kins], } 3 \text { uinals, } 9 \text { tuns and } 7 \text { katuns } \\ \text { F13a } & \text { from the joining together of } \\ \text { F13b } & \text { his katun, } \\ \text { E14 } & \text { Chief Double-Comb } \\ \text { F14 } & \text { Lord of Naranjo. }\end{array}$

The distance number at F12-E13 is counted from the date of the preceding clause on Stela 3, namely 3 Cauac 2 Pop [9.14.1.3.19], recorded at E4, E5. The latter date is very important in the reign of Smoking Squirrel. It appears as an Initial Series on Stela 2 and in a clause of Stela 30 (E7-F11). These texts indicate that the date is a 1 katun anniversary of Smoking Squirrel (Stela 2, B10-C10 and Stela 30, E9-E10). The reference at F13 on Stela 3 to the completion of "his katun" refers to this anniversary katun of Smok. ing Squirrel as the event from which the distance number at F12E13 is computed. Now, the date reached at F11-E12 is also an anniversary katun, namely, the 1 anniversay of the proposed accession date of Double-Comb. Thus, the text of Stela 3 relates a 1 katun anniversary of Smoking Squirrel to a 1 katun anniversary of Double-Comb.

What is the nature of this anniversary of Smoking Squirrel? As noted above, there is some expectation that anniversary dates commemorate accessions to power. That this is the case here is suggested by the best preserved anniversary clause, on Stela 30, which may be translated as follows: 


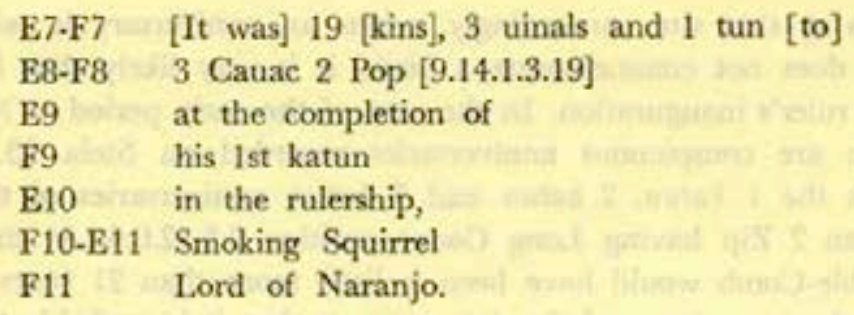

Unfortunately, the glyph at E10 is mostly obscure except for the locative prefix T59, ti, "in", which is followed by a T168, ahau, ahpo, ah, "lord ruler" element and other components.

Additional evidence on the above point comes from an analysis of the original event commemorated by the anniversary. This took place on 5 Cauac 2 Xul [9.13.1.3.19], a date recorded as an Initial Series on Stela 21. Although the text of Stela 21 is almost entirely effaced and the event glyph cannot be read, it is clear that being recorded as an Initial Series, the event was of major importance to Smoking Squirrel. The same date is also recorded in a clause of Stela 22 (F8-F11) and in this instance the event glyph, T228?.168:518:116, is well-preserved. The principal portion of this glyph combination, namely T168:518, occurs at Q11 on the East Panel of the Temple of the Inscriptions at Palenque where it appears in the predicate phrase of an accession clause (R9-Q12) of the great king Pacal. It also appears six times at Yaxchilan on Lintels 49 (B4, C1, D5), 37 (B2, B8) and 35 (B2). In each of these cases the name glyph of a ruler of Yaxchilan is preceded by an accession glyph and is followed by the T168:518 compound. These contexts tie the use of this glyph to accessions and by inference one can presume that 5 Cauac 2 Xul [9.13.1.3.19] marks the accession of Smoking Squirrel even though he was not yet 6 years old.

Stela 3 was erected to commemorate the first katun anniversary of the accession of Smoking Squirrel. Apparently, on this auspicious occasion, Smoking Squirrel chose to recall a first katun anniversary of his illustrious predecessor Double-Comb. It is to be expected that Double-Comb's katun anniversary was like-in-kind to that celebrated by Smoking Squirrel, that is, it was an anniversary of accession.

Following the suggested inauguration date on Stela 25 is the glyph shown in Fig. 4a. It bears some resemblance to an accession glyph frequently found at Palenque such as illustrated in Fig. 4b. Indeed, both have a similar composition and have the same main sign, the 
hand glyph T713a, although the upper elements differ. The evidence supporting the identification of the glyph in Fig. $4 \mathrm{a}$ as an accession glyph is very weak.

\section{Dynastic relations}

Altar 1 contains a clear parentage statement for Double-Comb. The phrases recording his mother and father follow in sequence, the former being illustrated in Fig. $5 \mathrm{a}$ and the latter in Fig. 5b. The leading glyphs in each case are relationship glyphs which may be paraphrased by "child of (the female parent)" and "child of (the male parent)", respectively. A discussion of similar relationship glyphs and parentage statements is given by Jones (1977:41-42).

The ultimate glyph in Fig. $5 \mathrm{~b}$ consists of a numerical prefix, "7", a T168, ahau, ahpo, ah, "lord, ruler", superfix and a T573, "change, succession", glyph as main sign. The ensemble can be glossed as "7th in the royal succession".

The birth clause depicted in Fig. 2 contains a phrase following Double-Comb's name, running from E3 to E10, commencing with a different "succession" compound. The second glyph, at F3, is the head of an anthropomorphic jaguar, balam, which can be identified with the god of the number 7 , and suggests a proper name. The glyph at G3 contains some elements which relate it to the event glyph at F1. One of these is a sky glyph with a T48 prefix and a numerical coefficient of 5. The other is a tun glyph of the type encountered earlier but this time with an animal-like prefix. The last glyph of the phrase occurs at E10 and is the Naranjo rulership glyph. Its presence here supports the notion that the glyph at F3 is a proper name (the glyph at G3 can be ruled out as a name glyph because of its relationship to the event glyph at F1) and indicates that the individual named there, $7 /$ Balam, occupied the throne of Naranjo. The chronology of Altar 1 demands that 7/Balam be a predecessor of Double-Comb and not a successor; thus E3 is best rendered as "successor of". The glyph at G3 might indicate that $7 /$ Balam had a count of 5 tuns at the time DoubleComb was born, signifying that he was at least 5 tuns, but less than 6 tuns, older than Double-Comb.

The central portion of Altar 1 is bounded by a quatre-foil cartouche which is shown in Fig. 2. The cartouche has an asymmetrical upening beneath the name of $7 /$ Balam. I consider that this design 
is intended to convey that its content serves as a parenthetic reference to $7 /$ Balam. Moreover, I also believe that the custom of writing glyphs in paired columns is broken here and replaced by tripled columns, above and below the central design, in order to accommodate this purpose. Glyph $\mathrm{M}$ in the central region exhibits death markings (death eye on forehead and percentage sign on check) and the principal motif itself is a fleshless skull wearing a "death eye" hat and "percentage sign" ear plugs. The obvious death symbolism in this central part of the altar is at variance with the hieroglyphic record which clearly celebrates the vitality of Double-Comb in presiding over three successive katun endings and whose life was to continue for some time yet as seen from Stela 25 and 27. The disparity can be resolved by interpreting the central portion as applicable to $7 /$ Balam, as advocated above, and not to Double-Comb. In this context, the death of $7 /$ Balam created the situation which allowed Double-Comb to assume power.

Further evidence for this interpretation comes from glyph 0 which consists of a yax prefix and a compound similar to that at $\mathrm{K} 4$ in Fig. 5b. In this instance, the compound has a coefficient of 8 and, following previous comments, should indicate the "8th in the royal succession". The yax prefix may indicate that $7 /$ Balam was only newly in office at the time of his death. Since Double-Comb's father was "7th in the royal succession" and 7/Balam, DoubleComb's predecessor, was "8th in the royal succession", then DoubleComb himself ought to be " 9 th in the royal succession". In fact, this very statement is recorded at A3-A4 on Stela 38 . The simplest explanation for these relationships is that $7 /$ Balam was an older brother of Double-Comb and that the "royal succession" referred to in the three records noted here ocurred within a single dynastic family.

A summary of the dynastic relations described is given in Table 2.

\section{A death at Naranjo}

The clause which follows the birth one on Altar 1 begins with a prior event, recalling the birth at $\mathrm{F} 1$, and continues with the current event which, in part, consists of a jawless skull with $u$ prefix at G12, possibly signifying $u$-cimi, "his death". The protagonist of the current event, recorded at I4, is Double-Comb and 
the date of the current event is 7 Akbal 11 Zotz' [9.5.10.1.3]. The grammatical structure of the clause would seem to imply that Double-Comb died on 7 Akbal 11 Zotz'. This raises a major problem as we have already seen evidence that Double-Comb was alive and acceded to the throne on $6 \mathrm{Kan} 2 \mathrm{Zip}[9.5 .12 .0 .4]$. There is much additional evidence attesting to the vitality of Double-Comb long after the death event of 9.5.10.1.3. For example, on Altar 1, DoubleComb is named at I11 after a sequence of three katun endings, 9.6.0.0.0 (H5-I6), 9.7.0.0.0 (H7-I8) and 9.8.0.0.0 (H9-H11). In the Maya inscriptions, this type of format indicates that the ruler so-named presided over the corresponding period endings.

It may also be noted that Stela 38 honours Double-Comb by referring to the katun endings 9.6.0.0.0 (A5-A7), 9.7.0.0.0 (A8-B1) and 9.8.0.0.0 (B2-B5) and then proclaiming him as "3 katun ahau" (B7), that is a "3 katun lord", a ruler who has presided over three katun endings. That such a monument, treating of a single ruler, should be erected more than 50 years after his death would be without precedent.

The inscription on Altar 1 ends with a clause which can be translated as follows:

$\begin{array}{ll}\text { J9 } & \text { At the "quarter-katun" event } \\ \text { K9 } & \text { he was the sprinkler of the carbon, } \\ \text { J10 } & \text { Chief Double-Comb } \\ \text { K10-J11 } & \text { [on] } 5 \text { Ahau } 3 \text { Ch'en [9.8.0.0.0] }\end{array}$

The glyph at K9, namely T1.710:87, is read as $u$-xaw-te, "he was sprinkler of the carbon", after a proposal of Victoria R. Bricker (1981). The clause would then signify that Double-Comb performed the ritual sprinkling at the katun ending and accordingly was still active at that time.

It will be recalled that when Smoking Squirrel celebrated his first katun anniversary as ruler, he mentioned a presumably similar anniversary of Double-Comb. It is most unlikely that Smoking Squirrel would choose to compare his anniversary with the anniversary of a posthumous event involving a dead king.

On Stela 31, Smoking Squirrel celebrated the passing of the midkatun at 9.14.10.0.0. At this time, he once again recalled DoubleComb. The pertinent clause can be translated as follows: 
I6-I7. [It was] 0 [kins], 0 uinals, 0 tuns and 8 katuns

J7-I8 [from] 8 Ahau (13 Pax) [9.6.10.0.0]

J8 [at the] end of a tun [of]

I9 Chief Double-Comb

J9 Lord of Naranjo.

Thus, Smoking Squirrel relates an event he celebrated to a similar event celebrated by Double-Comb more than 150 years earlier. One may presume that when Double-Comb celebrated the mid-katun at 9.6.10.0.0 he was as much alive as was Smoking Squirrel several generations later.

In the light of the hieroglyphic record, Double-Comb did not meet his end at 9.5.10.1.3. Hence the death referred to at G12 on Altar 1 is not that of the protagonist. From the preceding discussion dealing with 7/Balam, it can be argued that the death refers to DoubleComb's predecessor, detailed in the central cartouche. Because of that death Double-Comb became heir-apparent. An anticipation of his eventual accession seems to be recorded in the nominal phrase of the clause being considered at H3. This contains the glyph combination T168:518 previously studied with regard to accession statements. The chronological data shows that Double.Comb was a little over 19 years of age at the time of the death on Altar 1. According to the accession date proposed earlier, somewhat less than two years would pass before Double-Comb mounted the throne at Naranjo.

\section{Chronological events in the life of Chief Double-Comb}

In addition to the birth and accession of Double-Comb, his monuments pay homage to his longevity by referring to certain chronological milestones which he reached. Both Altar 1 and Stela 38 record that he presided over the katun endings 9.6.0.0.0, 9.7.0.0.0 and 9.8.0.0.0. As a result, he was given the title of "3 katun ahau" on Stela 38 at B7. Stela 25, as remarked previously, records the first, second and third katun anniversaries of his accession. It goes on to observe that Double-Comb was still holding power at 9.9.0.0.0 and then commemorates the three and a half katun anniversary of his accession at 9.9.2.0.4. Double-Comb lived through no less than 5 katun endings, running from 9.5.0.0.0 to 9.9.0.0.0. This feat is implied on Stela 27 at Apl where he is credited with "5 royal katuns". Finally, it may be noted that the penultimate phrase on 
Altar 1, at J5-K8, looks ahead to the baktun ending at 10.0.0.0.0 at which time Double-Comb would have been a little over 305 years old. The personal chronology of Double-Comb, following the reconstruction in this paper, is summarized in Table 3 .

\section{Epilogue}

The remaining two texts from the early period at Naranjo do not contain Naranjo emblem glyphs or rulership titles. In fact, they are monuments of a foreign ruler, Lord Storm-water Moon of Caracol. A thorough examination of their texts, particularly the Hieroglyphic Stairway, now in disarray, requires a study of the Caracol inscriptions which goes beyond this paper. Nevertheless, a few comments can be made. Lord Storm-water Moon's name glyph appears on Lintel 1 at $\mathrm{Cl}$ and $\mathrm{G} 4$ and on the Hieroglyphic Stairway at C1, T2 and V2a, From the paper of Beetz (1980: 9) it is known that Stela 3 from Caracol records the birth of Storm-water Moon at 9.7.14.10.8. Furthermore, Beetz notes that Lintel 1 begins with a damaged record of Storm-water Moon's birth date and continues with what is probably a parentage statement naming his mother, God C Star, at C4 and his father, Lord Water, at F3. The only other date on Lintel 1 marks the katun ending at 9.10.0.0.0.

The phrase running from L1b to L3 on the Hieroglyphic Stairway is of key importance to the understanding of the early history of Naranjo. Its event glyph consists of a Venus glyph over the main sign of the Naranjo emblem glyph. In the Thompson 534,285 correlation, the date corresponds to a possible first appearance of Evening Star. Lounsbury (personal communication) has suggested that the "Venus-over-emblem" configuration represents an astrologically timed military aggression on the site so specified. The associated date, at 9.9.18.16.3, would then mark the invasion of Naranjo by forces from Caracol. The resulting conquest of Naranjo led to its occupation for at least 11 years (the latest date on the Hieroglyphic Stairway occurs at 9.10.10.0.0), during which time Lintel 1 and the Hieroglyphic Stairway were completed.

The conquest of Naranjo occurred some 16 years after DoubleComb's latest known date and given his advanced age at that time it is certain that another ruler was on the throne of Naranjo at its downfall. About 40 years after the dedication of the Hieroglyphic Stairway, at 9.12.10.5.12, a woman from Tikal was given dominion 
over Naranjo. A little over five years later, at 9.12.15.13.7, she gave birth to a son, Smoking Squirrel, who went on to become the great ruler of Naranjo during its middle period. Because Smoking Squirrel recalled Double-Comb on two of his monuments and may have imitated his birth clause, it may be speculated that Smoking Squirrel's mother was related to the old Naranjo dynasty, some of whose members fled to Tikal at the time of its defeat,

Returning to Fig. 3 and the birth clause of Smoking Squirrel on Stela 24 it can be seen that there is a phrase from B15 to $\mathrm{C} 17$ which by analogy with Altar 1 should indicate that Smoking Squirrel was the successor of an earlier ruler of Naranjo whose name giyph is at B16-C16. At B15-C15 is a glyph which is comparable to one on Altar 1 at E2. Both glyphs contain the moon sign read as kal, "king, 20", and have a numerical coefficient, "15" on Altar 1 and "18" on Stela 24. The glyph on Altar 1 may signify either "the 15th king in succession" or "the 35th in succession", a reference which is presumably drawn from a list of kings of Naranjo. I favour the first reading as less demanding and more specific. According to this interpretation, Double-Comb would have been the 5th king of Naranjo and the 9 th in his dynasty. Smoking Squirrel, on the other hand, would be the 18th king in succession, a succession which may begin with the ruler named at B16-C16. This would imply that the latter was the first king of Naranjo. If Smoking Squirrel was the only king during the middle period, as appears to be the case, one can deduce that two others, the 16 th and 17 th, ruled at Naranjo, following the death of Double-Comb. Of these, no record survives, unless the name of the 17 th is preserved on the Hieroglyphic Stairway, no longer as a ruler but as a captive. If so, it has not yet been surely identified.

\section{REFERENCES}

Beetz, Carz. P.

1980 Camcol Thirty Years Later: A Preliminary Account of Two Beruis, Herngich Rulers. Expedition, 22, no. 3: 4-11.

1968 Estudios epigráficos II, Antropologia e historia de Guatemala, 20: $13-24$.

1973 Beitrage zum ver standnis der Inschriften von Naranjo, Société Suisse des Americanistes Bulletin, 37: 7-14.

Brtokrr, VictoriA R.

1981 Las ceremonias del año nuevo en los monumentos clásicos mayas. Paper presented at the XVII Mesa Redonda of the So- 
GrAнAM, IAN

ciedad Mexicana de Antropologia, San Cristóbal Las Casas, Chiapas, México, 21-27, June, 1981.

1978 Corpus of Maya Hieroglyphic Inscriptions, Vol. 2, Part 2, Peabody Museum of Archaeology and Bthnology, Harvard University, Cambridge.

GramaM, IAN and Eric von BUW

1975 Corpus of Maya Hieroglyphic Inscriptions, Vol. 2, Part 1, Peabody Museum of Arehaeology and Ethnology, Harvard University, Cambridge.

Jones, Christopher

1977 Inauguration Dates of Three Late Classic Rulers of Tikal, Guatemala, American Antiquity, 42: 28-60.

Louxsnury, FLovd G.

1980 Some Problems in the Interpretation of the Mythological Portion of the Hienoglyphic Text of the Temple of the Cross at Palenque, in Third Palenque Round Table, 1978, Part 2, pp. 99-115; Ed. by Merle Greene Robertwon, University of Texas Press, Austin.

Moriey, Syzvasus G.

1937-1938 The Inseriptions of Petein, Carnegie Institution of Washington, Pub. 437,5 vols., Washington.

Proskourlakofy, Tatiana

1960 Historical Implications of a Pattern of Dates at Piedras Negras, Guatemala, American Antiquity, 25:454-475.

Trompson, J. ERtc S.

1962 A Catalog of Maya Hieroglyphs, University of Oklahoma Press, Norman.

1971 Maya Hieroglyphic Writing: An Introduction, University of Oklahoma Press, Norman.

\section{ACKNOWLEDGEMENTS}

I am indebted to Peter Mathews for commenting on my preliminary study of chronology at Naranjo and for sending me a copy of his unpublished notes on dates from Naranjo. I thank Nikolai Grube for his comments on a preliminary version of this article.

I also thank the Social Sciences and Humanities Research Council of Canada for supporting this work with a research grant (410-81-0258). 
Table 1. Ione Count positions of dates frov the carly period at lieranjo.

Ch1af Doublo-Carib

St. 38 N1.t.1 St.25
Lord Storri-inter Moon

Lin.1 HS

7. 2. 4. 5.24 $13 \mathrm{Ix} 22 \mathrm{xw2}$

8. 5.18. 14. $0 \quad 7$ Ahau 3 Kankin

9. 4.20, 8.27 7 Caban 5 Kayab

9. 5.70. 1. $3 \quad 7$ Akbal 11 Zotz'

9. $5.12 .0 .4 \quad 6 \operatorname{Kan} 3.23 \mathrm{p}$ *

9. 6. 0, 0, $0 \quad 9$ Ahau 3 Uаўb

9. 6.12. 0. $4 \quad 4$ Kan 7 Pax

9. 7. 0.0.0 ? Ahat 3 Kankln

9.7.12.0.4 2 Kon 7 Zao

9. $7.2 h_{0} 20.83$ Ianes 16 th

9. B. 0. 0, $0 \quad 5$ ther $3 \mathrm{Ch}$ 'en

9. 8.12. $0.4 \quad 13 \mathrm{Kan} 7 \mathrm{Xm}$

9. 9. 0. 0.0 3 Nhas 3 2ots'

9. 9. 2. $0.412 \operatorname{Kan} 18 \mathrm{zp}$

? 9. 9.14. 3.5 12 Chlcohan $18 \mathrm{zlp}$

9. $9.17 .11 .1 \mathrm{~h} \quad 13$ Ix $12 \mathrm{zaO}$

9. 9.18.16. 37 Akbal 16 van

9.10. 0. 0. 01 Ahau $8 \mathrm{Kayab}$

9.10. 3. 2.122 BO O POP

9.10. 4.16. $2 \quad 8$ Ik 5 Kanksn

9.10.10. 0. 013 Ahau 18 Kanidn

10. 0. 0. 0. $0 \quad 7$ Ahau $18 \mathrm{zip}$

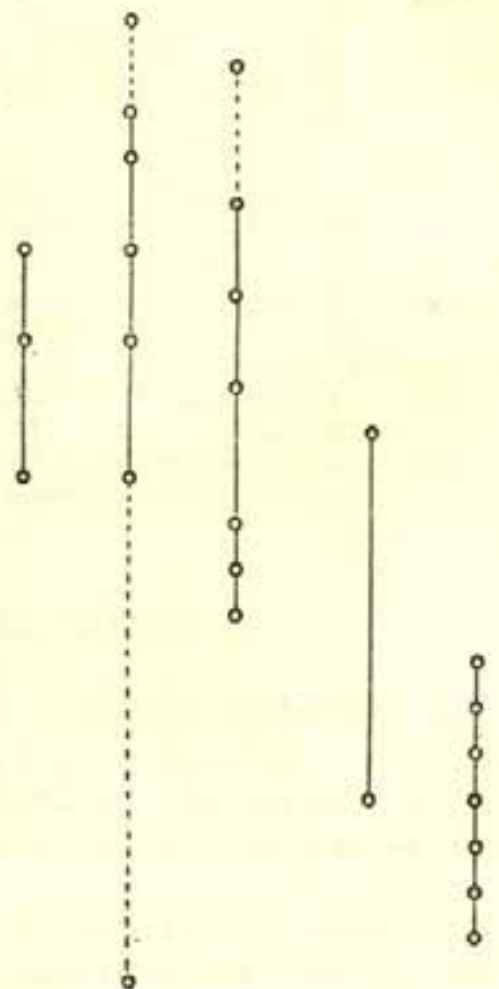

\footnotetext{
* 6 Man 2 21p oxpootod **

12. Kan $17 \mathrm{Zlp}$ expected
} 
Table 2. Dynastic relations in the early period at Naranjo.

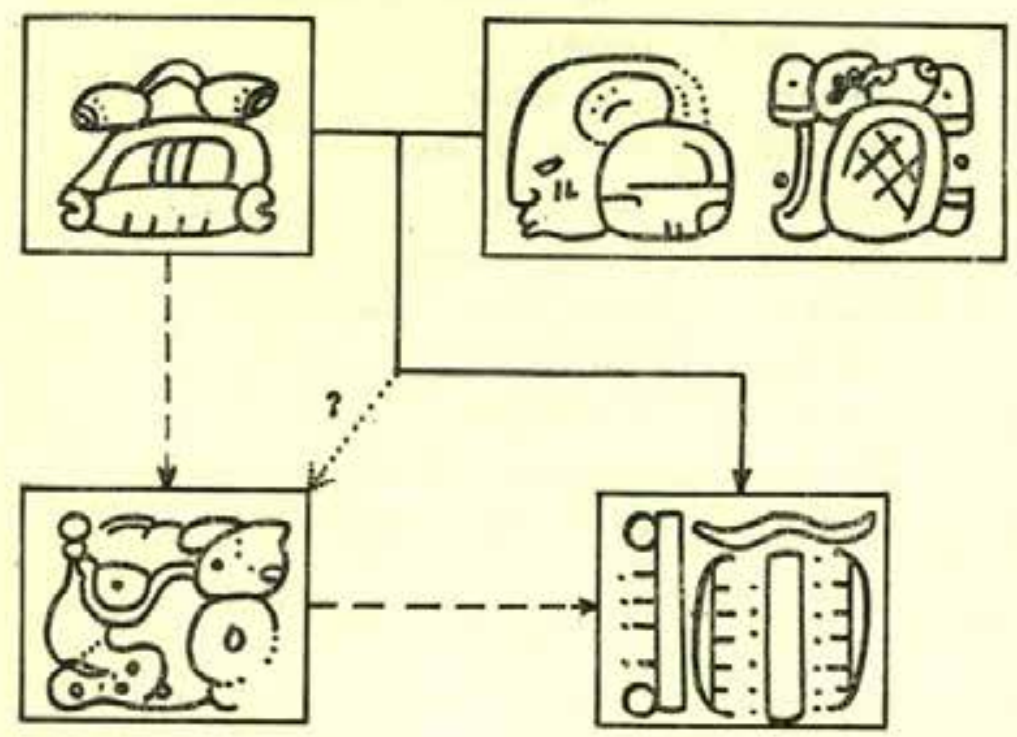

ISine of descont:

Idno of gruccession: $--\rightarrow$ 
Table 3. A personal chronology for Chief Double-Comb of Naranjo.

Long Count Position

Event

9.4.10.8.17 birth

9.5.10.1.3 death of Balam and heir-apparency

9.5.12.0.4

9.6.0.0.0

9.6 .12 .0 .4

9.7 .0 .0 .0

9.7.12.0.4

9.8.0.0.0

9.8.12.0.4.

9.9 .0 .0 .0

9.9 .2 .0 .4

10.0 .0 .0 .0 accession

katun ending

1 katun in office

katun ending

2 katuns in office

katun ending; 3 katun lord

3 kafuns in office

katun ending

3 katuns and 10 tuns in office

baktun ending; prophetic
Chronological Age

0

19.10 .6

1.1.9.7

1.9 .9 .3

2.1.9.7

2.9 .9 .3

3.1.9.7

3.9 .9 .3

4.1.9.7

4.9 .9 .3

4.11 .9 .7

15.9 .9 .3 

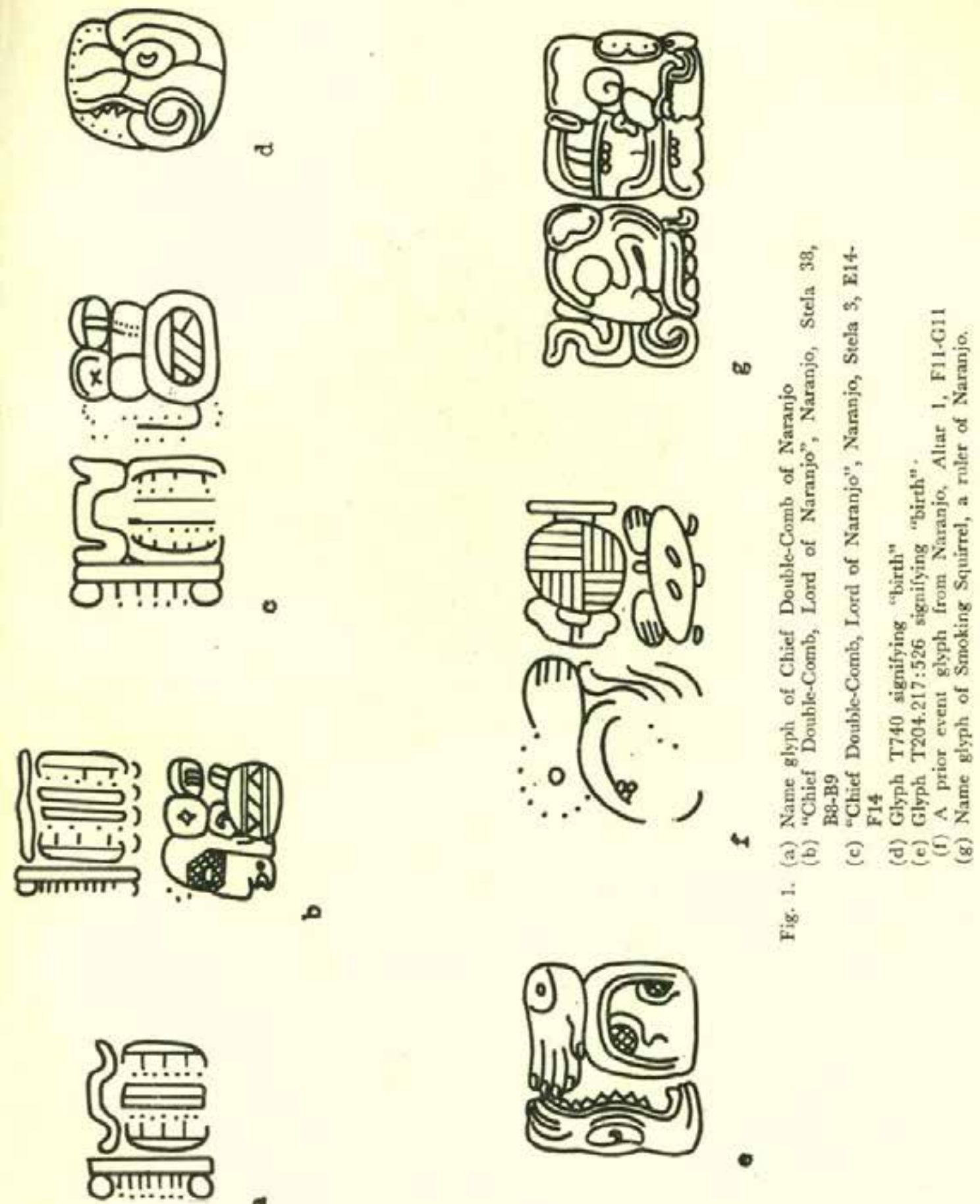

c) 
E $\quad$ F $\quad G$

1

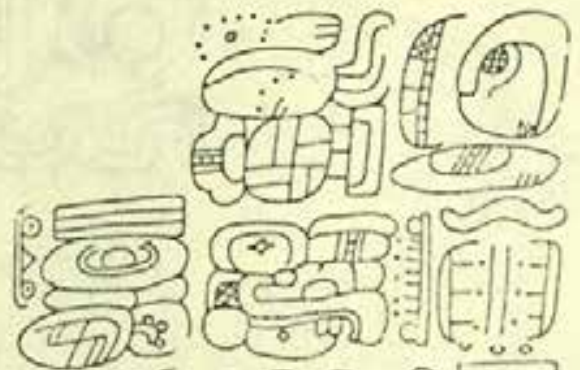

3

$?$

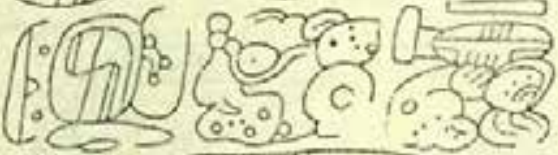

10

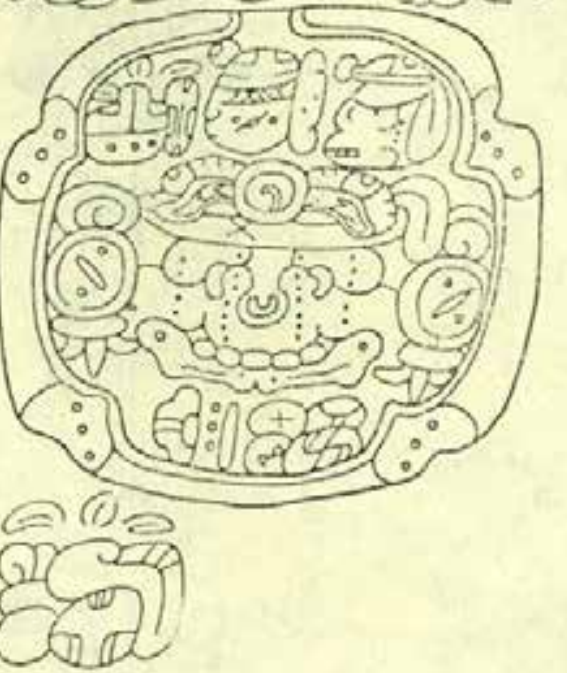

I $M, N$

Fig. 2. Naranjo, Altar 1, F1-E10 and L-0 (drawing by I. Graham). 


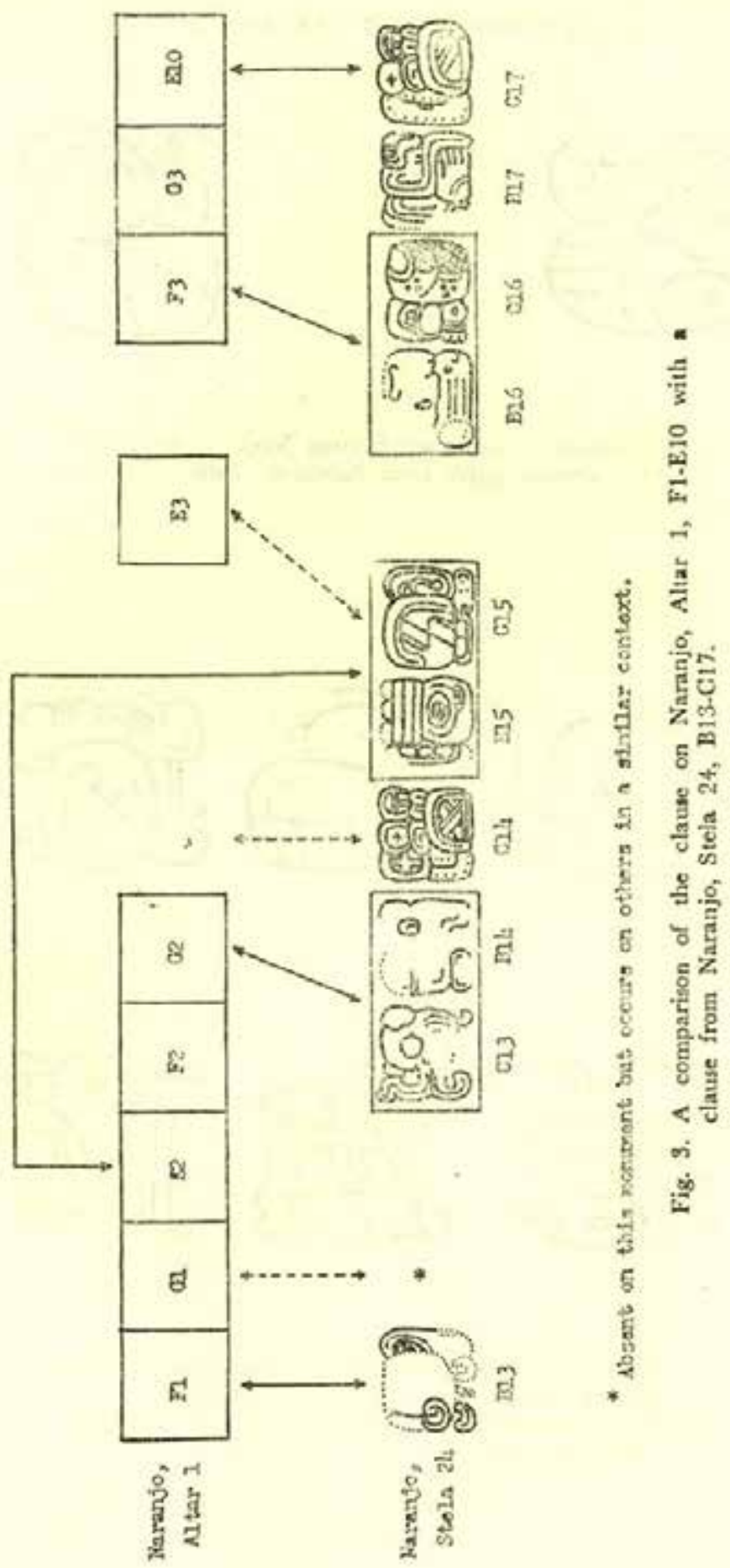

Estudios de Cultura Maya. Vol. XV, 1984

Instituto de Investigaciones Filológicas/

Centro de Estudios Mayas, UNAM

http://www.iifilologicas.unam.mx/estculmaya/ 


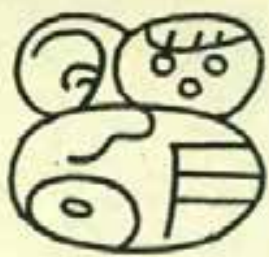

a

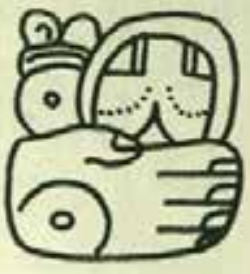

b

Fig. 4. (a) A possible accession glyph from Naranjo, Stela 25, B9

(b) An accession glyph from Palenque, Tablet of the Cross, Q15.
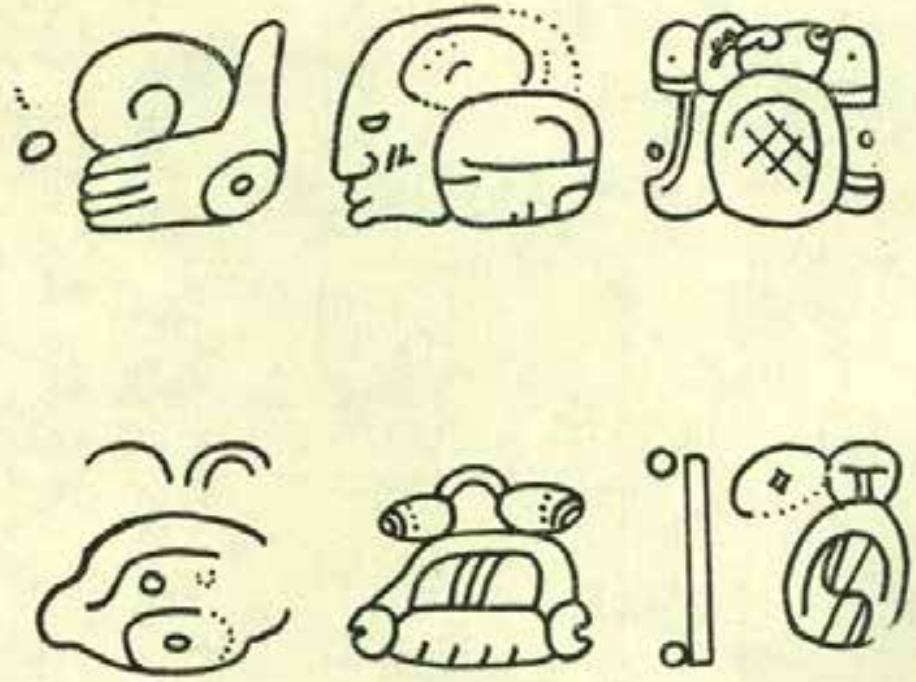

Fig. 5. (a) Phrase recording the mother of Chief Double-Comb, Naranjo, Altar 1, I12-J3

(b) Phrase recording the father of Chief Double-Comb, Naranjo, Altar 1, K3-K4. 